\title{
DIAGNÓSTICO DA MORTALIDADE DE PEDESTRES NO BRASIL
}

\author{
G. P. Caldeira'; B. P. S. Branco²; J. T. Bastos ${ }^{3}$ \\ ${ }^{1,2,3}$ Universidade Federal do Paraná, ${ }^{2}$ Observatório Nacional de Segurança Viária \\ gabrielcaldeiral@ufpr.br $r^{l}$, beatriz.branco@onsv.org.br ${ }^{2}, j t b a s t o s @ u f p r . b r^{3}$
}

\begin{abstract}
Resumo: Historicamente no Brasil o tratamento do pedestre no trânsito das cidades foi negligenciado pelo planejamento urbano e de transportes. Apesar de atualmente representarem o modo responsável pela maior quantidade de viagens diárias nas cidades brasileiras, este ainda não é priorizado na elaboração das políticas públicas e construção de uma infraestrutura conveniente às suas necessidades. Como consequência, os pedestres foram as principais vítimas fatais de acidentes de trânsito no país entre 2000 e 2015 (chegando a 148 mil mortes). Tendo em vista este cenário alarmante, o objetivo deste artigo é fornecer um diagnóstico acerca da mortalidade de pedestres no Brasil, a partir de uma série histórica de indicadores no período 2000-2015 coletados de fontes oficiais. Como resultado, identificou-se uma redução contínua da participação dos pedestres nas mortes no trânsito no país - passou-se de 30\% em 2000 para 18\% em 2015. Um dos fatores capazes de ter contribuído para tal variação é o crescimento na aquisição e utilização de motocicletas. Apesar disso, a situação ainda é crítica, com taxas de mortalidade de 3,41 pedestres por 100 mil habitantes - valor 2,7 vezes maior que a taxa da Uniáo Europeia. Nesse sentido, destaca-se a elevada redução na participação dos pedestres no total das vítimas fatais do trânsito. Por fim, entende-se a necessidade de enxergar o modo a pé sob um olhar técnico na gestão municipal do trânsito. Dessa forma, a avaliação da qualidade do transporte a pé utilizando indicadores padronizados é fundamental para o monitoramento e a gestão das informaçóes acerca desse modo de transporte.
\end{abstract}

Palavras-chave: Pedestres, Segurança Viária, Brasil, Mortalidade.

\begin{abstract}
Historically in Brazil the pedestrian treatment in urban traffic was neglected in urban and transportation planning. Although they actually represent the mode responsible for the higher number of daily trips in Brazilian cities, they are not prioritized in the elaboration of public policies and in the construction of an infrastructure convenient to their needs. As a consequence, the pedestrians were the main victims of traffic accidents in the country between 2000 and 2015 (reaching 148 thousand fatalities). Due to this alarming scenery, the aim of this paper is to provide a diagnosis about pedestrian's mortality in Brazil through a historical series of indicators from official sources in the period 2000-2015. As a result, a continuous reduction in the pedestrian participation on traffic fatalities in the country was identified - from $30 \%$ in 2000 to $18 \%$ in 2015 . One of the factor that could have contributed to this variation is the motorcycle acquisition and usage growth. Even though, the situation is still critical, with mortality rates of 3.41 pedestrian per 100 thousand inhabitants - value 2.7 times higher than the European Union rate. Thus, it is worth to stress the significant reduction of pedestrian's participation in total traffic fatal victims. Finally, there is the need to have a technical view over the pedestrian mode in municipal traffic management. Therefore, the evaluation of walking transportation quality using standard indicators is fundamental for the monitoring and related information management.
\end{abstract}

Keywords: Pedestrians, Road Safety, Brazil, Mortality. 


\section{Introduçáo}

Caminhar é a forma mais democrática e sustentável de deslocamento, por meio da qual todas as pessoas conseguem se locomover sem a necessidade de pagamento de tarifa ou aquisição de um bem móvel [1]. Nos primórdios da civilização, o caminhar era a única alternativa de deslocamento para as pessoas. A partir do desenvolvimento das primeiras cidades, formas mais variadas de deslocamentos foram sendo incorporadas ao dia a dia da população. No entanto, a participaçãa do modo a pé sempre permaneceu bastante expressiva. Mais recentemente, com a era da industrialização e a incorporação dos meios motorizados na matriz de deslocamentos das cidades, o modo a pé foi perdendo sua importância nas pautas do planejamento urbano, de modo que os estudos de engenharia de tráfego passaram a ter seu foco cada vez mais voltado para o transporte motorizado [2;3].

No que diz respeito à participação do modo a pé na matriz de deslocamentos realizados nas cidades, tem-se, de acordo com Sistema de Informaçóes da Mobilidade Urbana da ANTP, que o número de viagens realizadas a pé em 2014 foi de 23,4 bilhóes, o que representa 36,5\% das viagens realizadas nas cidades do Brasil - para as viagens realizadas por transporte coletivo, automóveis, motocicletas e bicicletas tem-se uma participação de 29\%, 27\%, 4\% e 4\% respectivamente. Vale destacar também, que esse número varia de acordo com o porte das cidades, podendo chegar a quase $40 \%$ das viagens realizadas a pé nas cidades com menos de 250 mil habitantes [4].

A partir dos dados expostos, deve-se reconhecer a importância do papel do modo a pé na mobilidade humana nas cidades brasileiras e, dessa forma, garantir a oferta de um ambiente adequado para esses deslocamentos por meio da oferta de uma rede de transporte a pé [5]. As características dos usuários do modo a pé são diversas, tanto em relação à existência de necessidades específicas associadas ao ser humano (pedestres idosos, crianças, gestantes, portadores de necessidades especiais, etc.), como em relação à energia e o tempo gasto no deslocamento e, finalmente, em relação às distâncias percorridas. Tal conjunto de condiçôes de contorno dispostas sobre a oferta de infraestrutura urbana existente determinam o nível de conveniência e segurança de andar a pé.

\subsection{Sobre a segurança viária e os pedestres}

Sabe-se que os pedestres compóem uma parcela substancial nas mortes ocasionadas por acidentes de trânsito. Em todo o mundo, o número de pedestres mortos em acidentes de trânsito chegou a 273 mil pessoas em 2013, o que corresponde a 22\% do total de mortes [6]. Nas cidades, são muitos os fatores de risco enfrentados pelos pedestres no trânsito. Entre eles, a Organização Panamericana de Saúde - OPAS [7] destaca: a velocidade incompatível, o uso de álcool, problemas na infraestrutura para pedestres, iluminação pública deficiente (prejudicando a visibilidade em travessias) e baixo nível de fiscalização do trânsito. 
No que se refere ao fator da velocidade, pode-se dizer que há uma incompatibilidade entre os limites de velocidades permitidos para vias urbanas de acordo com o Código de Trânsito Brasileiro - CTB [8] e o nível de interação existente entre usuários motorizados e não motorizados (pedestres e ciclistas). Estão previstos no CTB limites de até $80 \mathrm{~km} / \mathrm{h}$ de velocidade - o que, para usuários vulneráveis como os pedestres, acaba representando elevado risco de lesóes graves e mortes. Na verdade, já para velocidades da ordem dos $50 \mathrm{~km} / \mathrm{h}$, a probabilidade de um pedestre sobreviver em um atropelamento é muito baixa, como demonstra a Figura 1.

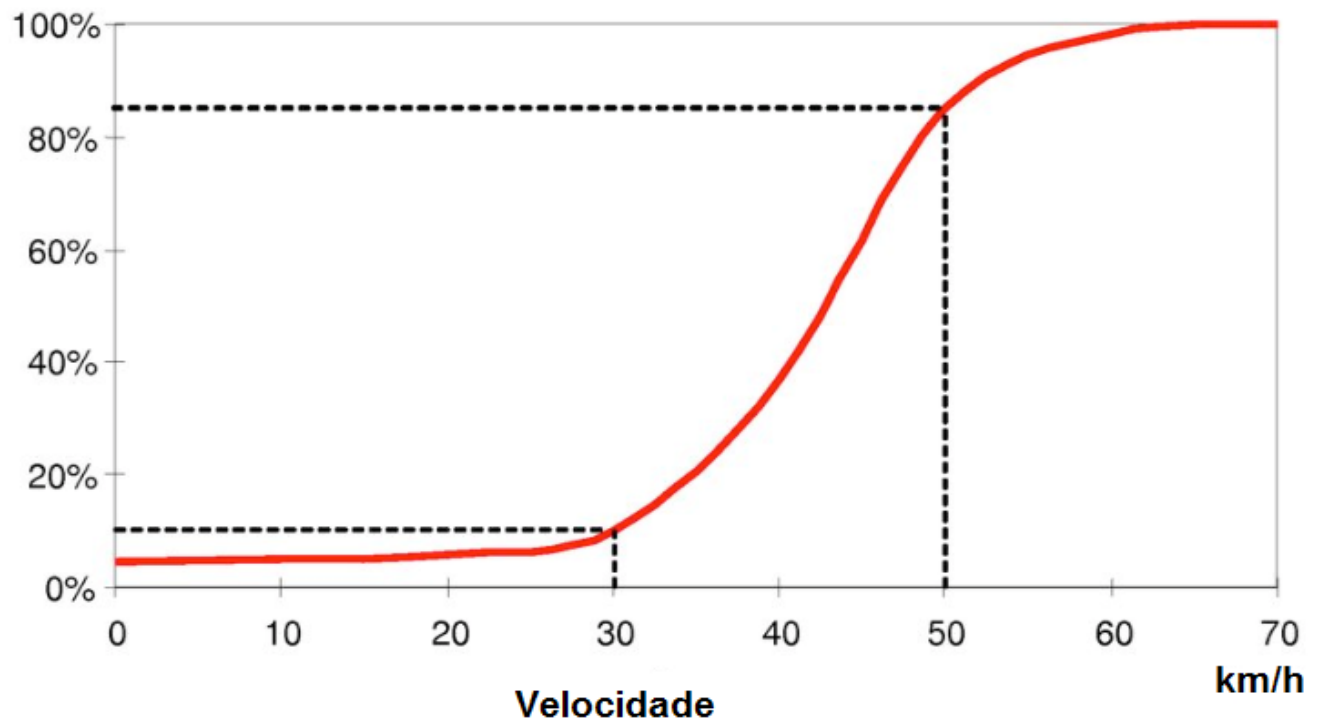

Figura 1 - Probabilidade de morte em caso de atropelamento de pedestre segundo velocidade do veículo. Fonte: OECD [9].

No que se refere a interação dos pedestres com a infraestrutura e os automóveis, alguns estudos têm demonstrado que é muito importante compreender o comportamento dos pedestres na sua circulação dentro do ambiente construído nas cidades - analisando também as diversas características relacionadas a essa circulação, levando em conta por exemplo o gênero e a idade dos pedestres. Como demonstrado por Ferenchak [10], na Índia, o tempo de espera em travessias para mulheres chega a ser o dobro do tempo de espera dos homens, indicando um maior nível de tolerância à espera por parte do gênero feminino. $\mathrm{O}$ mesmo estudo salienta também que os homens têm um comportamento muito mais agressivo que as mulheres na condição de pedestre, náo respeitando a infraestrutura existente, como as faixas de pedestres, e consequentemente causando mais conflitos com os automóveis.

$\mathrm{Na}$ Hungria, os dois principais erros (relacionados aos acidentes) cometidos por condutores ao cruzar as faixas de pedestres são: velocidade elevada e falta de prioridade ao pedestre. No que diz respeito ao erro por parte do pedestre (apesar de teoricamente o pedestre ter prioridade na maioria das situaçôes), o principal fator apontado é a falta de atenção na travessia [11]. 
A partir da exposição da relação do modo a pé com o trânsito e a infraestrutura das cidades e do entendimento dos riscos associados aos mesmos, o objetivo do presente artigo é realizar um diagnóstico da mortalidade de pedestres no Brasil.

\section{Metodologia}

A metodologia utilizada para a construção do diagnóstico da mortalidade dos pedestres compóe-se de duas etapas. A primeira consistiu na coleta dos dados secundários no período 2000-2015 referentes a: vítimas fatais em atropelamentos junto ao Ministério da Saúde no banco de dados do DATASUS [12]; histórico da frota de veículos de acordo com o Departamento Nacional de Trânsito - DENATRAN [13]; e, por fim, a população conforme Instituto Brasileiro de Geografia e Estatística - IBGE [14]. A segunda etapa deu-se, entáo, pela análise dos dados coletados realizada em âmbito nacional. O fluxograma abaixo expressa a metodologia utilizada para a análise da evolução das mortes de pedestres no Brasil (Figura 2).

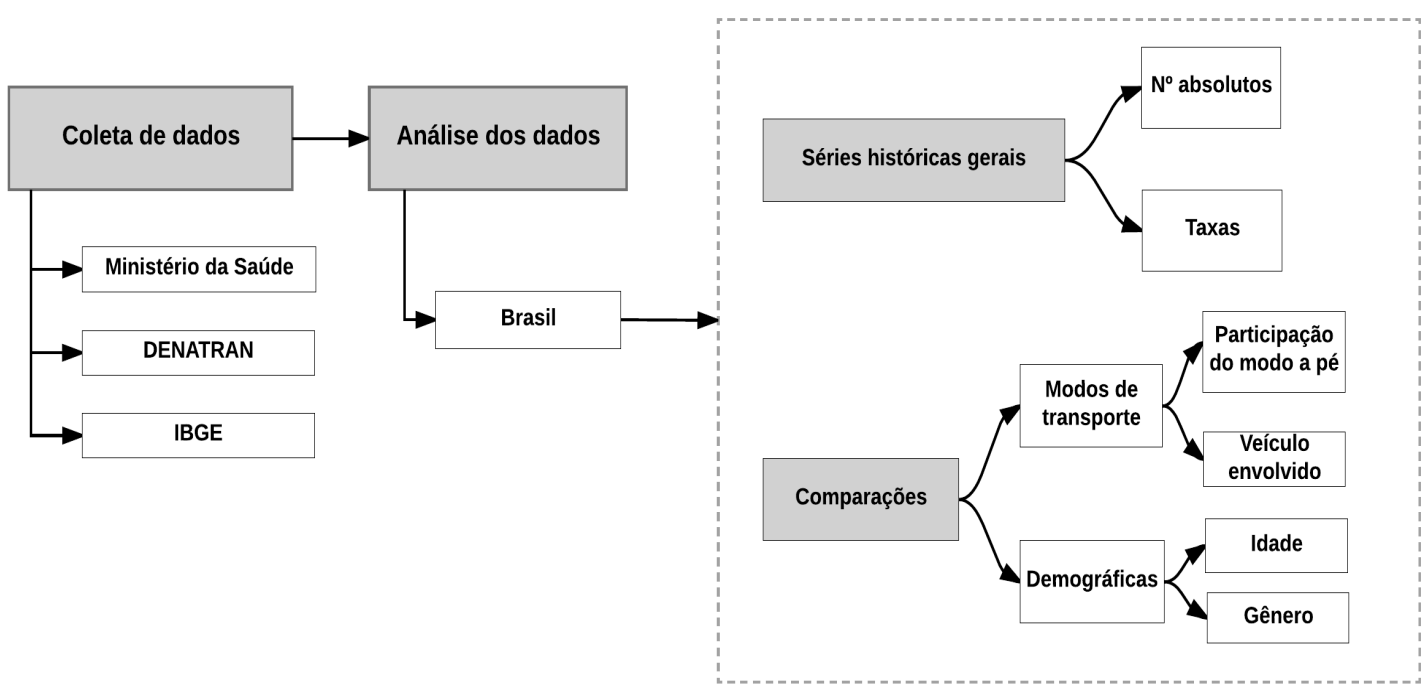

Figura 2 - Fluxograma do processo de análise da situaçấo da mortalidade de pedestres no Brasil Fonte: Elaboração do autor.

Os dados de mortes no trânsito coletados no DATASUS são classificados a partir dos códigos V01 a V89 da Classificação Internacional de Doenças (CID).

\section{Resultados}

No período entre 2000 e 2015 o número absoluto de óbitos de pedestres apresentou uma tendência de aumento até 2005, quando então iniciou-se um período de redução até 2009. Entretanto, 
em 2010, verifica-se um pico no número de óbitos de pedestres. A partir de então, tem-se novamente tendência de redução até 2015, com o menor valor no período, correspondente a 6.979 óbitos de pedestres (ver Figura 3). Devido ao reduzido crescimento populacional no período, a mesma análise vale para a taxa de óbitos de pedestres por 100 mil habitantes. Em 2015, a taxas de óbitos de pedestres por 100 mil habitantes foi de 3,41 - valor 2,7 vezes maior que a taxa da União Europeia [15]. Por outro lado, o Brasil passou por um intenso processo de motorização, de modo que as taxas de óbitos de pedestres por 10 mil veículos apresentaram uma redução praticamente contínua ao longo do período (ver Figura 3).

\section{Taxas de Mortalidade de pedestres}

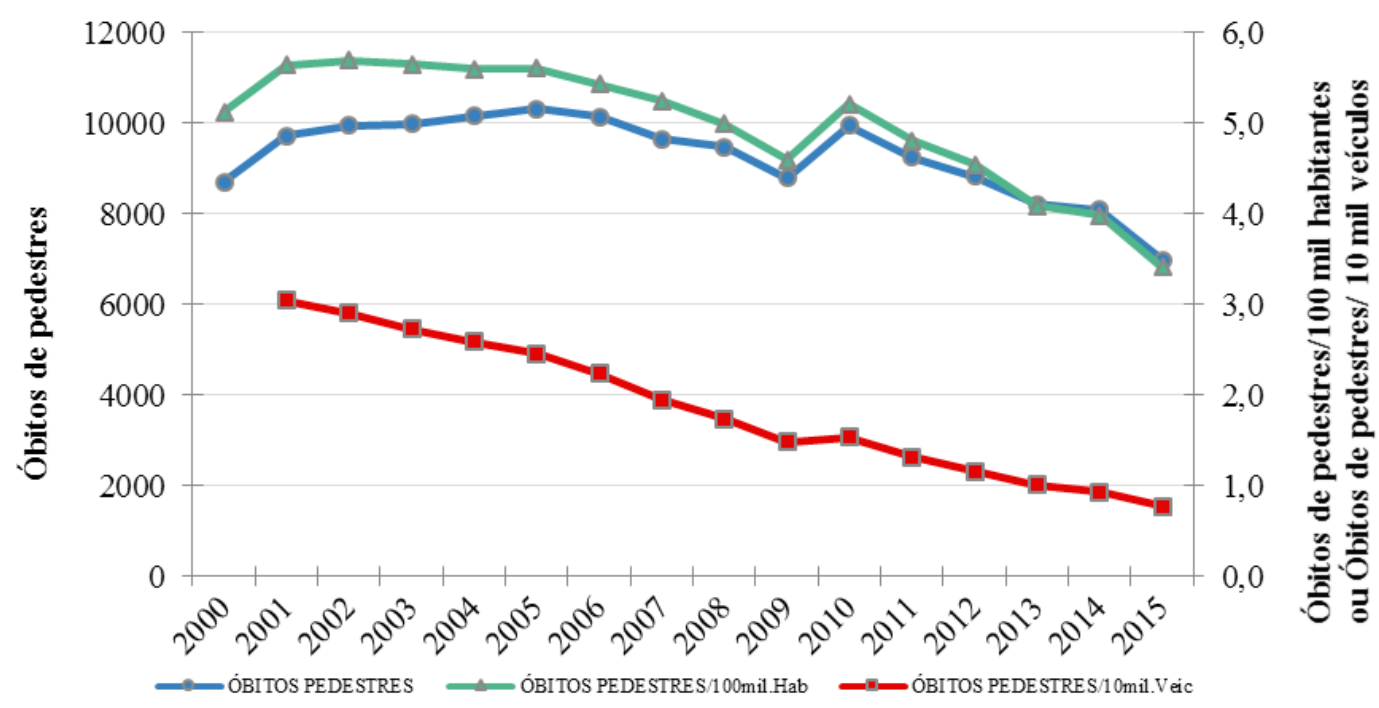

Figura 3 - Gráfico de Taxas de mortalidade de pedestres: $\mathrm{n}^{\circ}$ óbitos absolutos, óbitos por 100 mil habitantes e por 10 mil veículos.

Fonte: Brasil (2017).

Além de avaliar os números absolutos e as taxas de óbitos de pedestres no país, é importante analisar também a participação desses usuários no total de óbitos. Nesse sentido, destaca-se a elevada redução na participação dos pedestres no total das vítimas fatais do trânsito - passou-se de $30 \%$ em 2000 para 18\% em 2015. Um dos fatores capazes de ter contribuído para tal variação é o crescimento na aquisição e utilização de motocicletas, pois a participação desses usuários no total de mortes no trânsito passou de 8\% em 2000 para 31\% em 2015. Ainda em relação à distribuição dos óbitos segundo modo de transporte da vítima, salienta-se a redução da categoria "outros/não identificados" - o que indica uma melhoria na precisão na coleta da informação (ver Figura 4). 


\section{Distribuição por modo em2000}

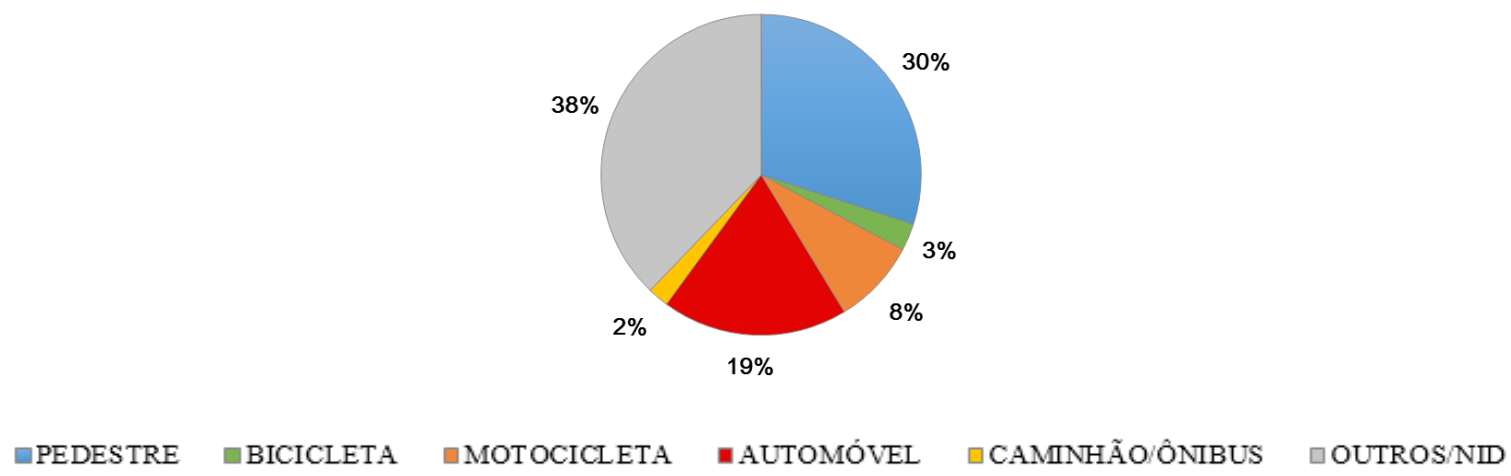

Figura 4 - Distribuição de óbitos por modo 2000-2015.

Fonte: Brasil (2017).

Veículo atropelador - 2000

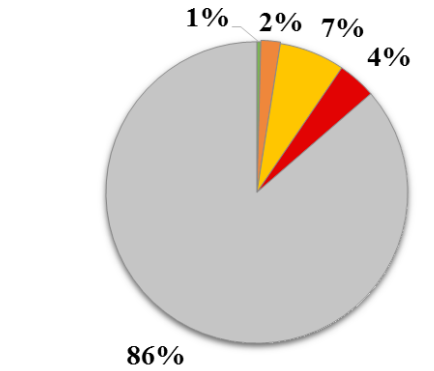

Veículo atropelador - 2015

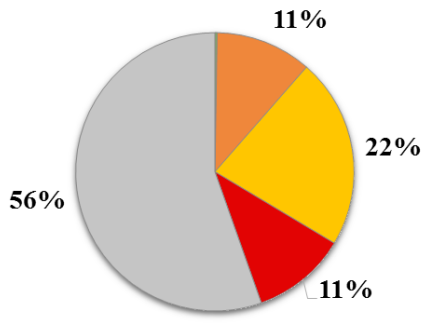

\section{•BICICLETA $\square$ MOTOCICLETA $\square$ AUTOMÓVEL $=$ CAMINHÃO/ÔNIBUS $\square$ OUTROSNDD}

Figura 5 - Distribuição segundo veículo atropelador 2000-2015.

Fonte: Brasil (2017).

No caso dos atropelamentos, deve-se analisar também a categoria do veículo envolvido. $\mathrm{O}$ automóvel era o principal veículo envolvido em atropelamentos fatais, seguido dos caminhóes/ônibus e das motocicletas no ano 2000. Em 2015, o automóvel permaneceu como o principal veículo envolvido em atropelamentos fatais, seguido dos caminhóes/ônibus/motocicletas. Entretanto, é necessário levar em consideração que a interação entre pedestres e automóveis é muito mais frequente que a interação com os demais modos (ver Figura 5). É preocupante a elevada proporção da categoria “outros/não identificado" - 86\% no ano 2000 e 56\% em 2015 - visto que não se conhece a categoria de veículo envolvida no atropelamento, o que dificulta o planejamento de contramedidas específicas para a reduçáo do risco.

Em relação à idade das vítimas pedestres, levando-se em consideração o número de habitantes em cada faixa etária, calculou-se a taxa de óbitos de pedestres por 100 mil habitantes (ver Figura 6). De acordo com essa análise, pode-se indicar que as faixas etárias de 20 a 29 anos e de 60 anos ou mais apresentam as maiores taxas de mortalidade. As razóes para tal diferença podem estar associadas aos 
comportamentos de risco mais recorrentes na faixa etária dos 20 aos 29 anos e à maior vulnerabilidade associada aos usuários idosos (60 anos ou mais).

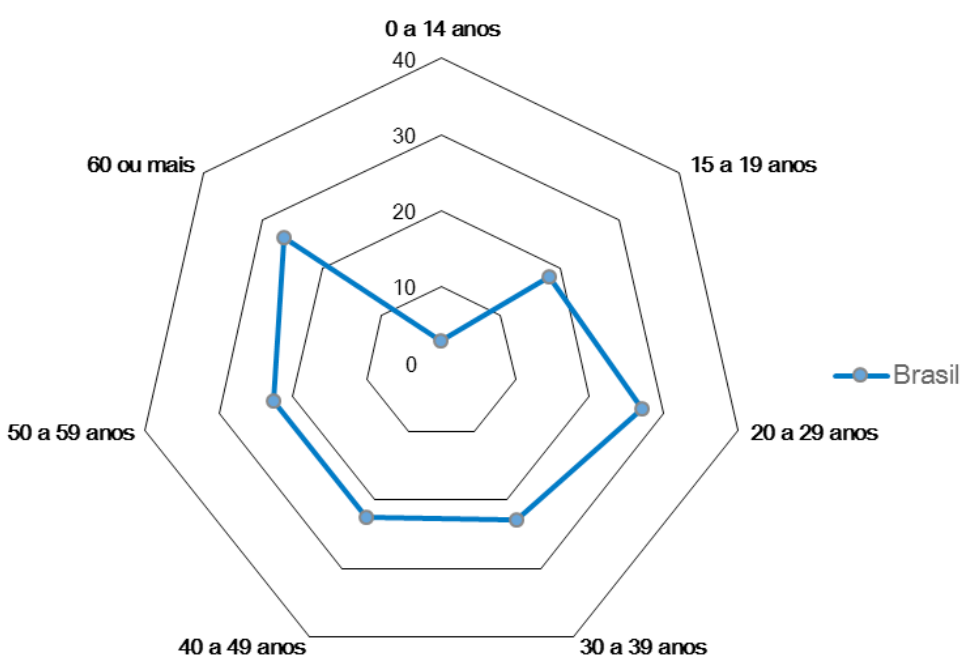

Figura 6 - Taxa de óbitos por 100 mil habitantes segundo faixa etária em 2015. Fonte: Brasil (2017).

No tocante ao gênero das vítimas fatais dos atropelamentos é possível observar a maior participação de homens (82\%) em relação às mulheres (18\%). A taxa de óbitos em atropelamentos por 100 mil habitantes é aproximadamente 5 vezes maior entre os homens (taxa de 31,5 para homens e de 6,6 para mulheres) (ver Figura 7). Apesar da conclusão mais óbvia de que homens apresentariam um risco maior de serem atropelados que mulheres, a comparação de taxas de óbitos por 100 mil habitantes pode não ser suficiente e tampouco conclusiva para identificar qual gênero apresenta maior risco no trânsito. Isso é principalmente válido em cenários com pouca disponibilidade de informaçôes que possibilitem adotar os níveis de desagregaçáo desejáveis nas análises e utilizar uma medida adequada de exposição, como é o caso do Brasil.

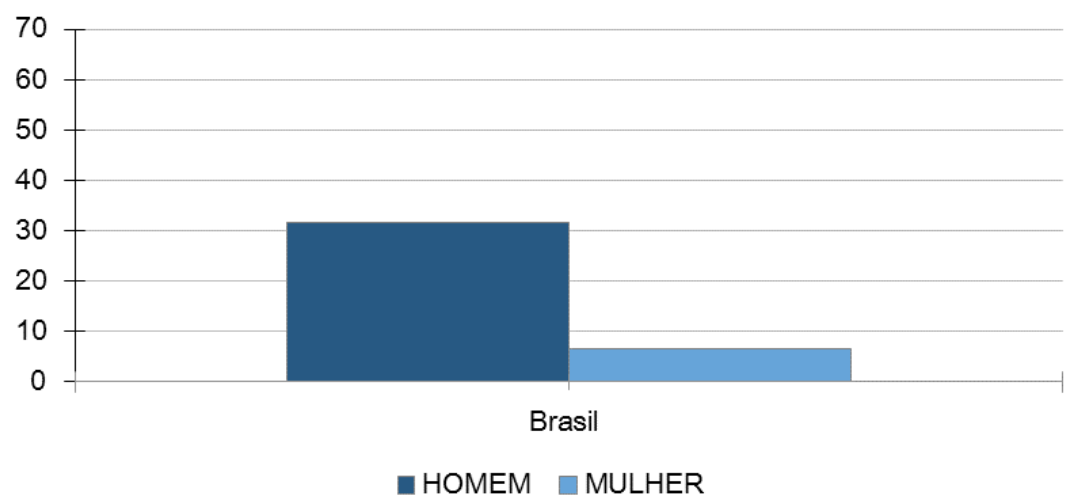

Figura 7 - Taxa de óbitos por 100 mil habitantes segundo gênero em 2015.

Fonte: Brasil (2017). 


\section{Conclusóes}

A partir do conjunto de informaçóes apresentadas neste documento fica explícita a necessidade de direcionar maior atenção aos usuários do modo a pé no país, tanto por sua representatividade nos deslocamentos diários, quanto por sua evidente vulnerabilidade nas análises de âmbito nacional. A lógica de negligenciamento das viagens a pé no campo do planejamento de transportes e engenharia de tráfego precisa ser modificada, visto que o modo a pé demanda investimentos em infraestrutura, em geral, mais baixos (em comparação aos modos motorizados) e impactam positivamente parcela substancial das viagens nas cidades brasileiras. Portanto, medidas de valorização do transporte a pé tendem a estar associadas a um elevado nível de racionalidade (baixo custo por usuário atendido).

Enxergar o modo a pé sob um olhar técnico na gestão municipal do trânsito é necessário, apesar de sua característica intrínseca ao ser humano. Dessa forma, a avaliação da qualidade do transporte a pé utilizando indicadores padronizados é fundamental para o monitoramento e a gestão das informaçóes acerca desse modo de transporte. A garantia de níveis seguros de mobilidade para pedestres, em toda sua diversidade de características - contemplando portadores de necessidades especiais - é um indicativo da presença de uma cultura de segurança viária, já observada em alguns países que demonstraram ser possível atingir níveis mínimos de risco no trânsito.

\section{Referências}

[1] BASTOS, Jorge Tiago; CALDEIRA, Gabriel Pereira; BRANCO, Beatriz Pontes. Relatório Estatístico de Segurança Viária: Pedestres 2017. Indaiatuba: Observatório Nacional de Segurança Viária, 2017. Disponível em: <http://www.onsv.org.br/quem-anda-a-pe-precisa-de-mais-atencao/>. Acesso em: 15 nov. 2017.

[2] FERRAZ, Antonio Clóvis Pinto; TORRES, Isaac Guilhermo Espinosa. Transporte Público Urbano. 2. ed. São Carlos: Rima Editora, 2004. 428 p.

[3] VASCONCELLOS, Eduardo Alcântara de. Políticas de Transporte no Brasil: A construção da mobilidade excludente. Barueri: Manole, 2014. 289 p.

[4] ASSOCIAÇÃO NACIONAL DE TRANSPORTES PÚBLICOS (ANTP) (Brasil) (Org.). Relatório Geral 2014. São Paulo, 2016. 96 p. Disponível em: <http://files.antp.org.br/2016/9/3/sistemasinformacao-mobilidade-geral_2014.pdf>. Acesso em: 14 set. 2017.

[5] GOLD, Philip (Brasil). Qualidade de Calçadas no Município de São Paulo. São Paulo: Gold Projects, 2004.

[6] WORLD HEALTH ORGANIZATION (Geneva) (Org.). Global Status Report on Road Safety 2015. Switzerland, 2015. Disponível em: <http://www.who.int/violence_injury_prevention/road_safety_status/2015/en/>. Acesso em: 14 set. 2017.

[7] ORGANIZAÇÃO PAN AMERICANA DA SAÚDE (OPAS). (Org.). Segurança de pedestres: Manual de segurança viária para gestores e profissionais da área. Brasília, 2013.

[8] BRASIL. Lei no 9.503, de 23 de setembro de 1997. Código de Trânsito Brasileiro. Disponível em: <http://www. planalto.gov.br/ccivil_03/LEIS/L9503.htm>. Acesso em: 9 set. 2017.

[9] ORGANISATION FOR ECONOMIC CO-OPERATION AND DEVELOPMENT (OECD) (França) (Org.). Speed Management. Paris, 2006. Disponível em: <https://www.itf-oecd.org/sites/default/files/docs/06speed. pdf $>$. Acesso em: 14 set. 2017. 
[10] FERENCHAK, Nicholas N. Pedestrian age and gender in relation to crossing behavior at midblock crossings in India. Journal of Traffic and Transportation Engineering (english Edition), [s.1.], v.3, n.4, p.345-351, ago. 2016. Elsevier BV. http://dx.doi.org/10.1016/j.jtte.2015.12.001.

[11] MAKO, Emese; SZAKONYI, Petra. Evaluation of Human Behaviour at Pedestrian Crossings. Transportation Research Procedia, [s.1.], v. 14, p.2121-2128, 2016. Elsevier BV. http://dx.doi.org/10.1016/j.trpro.2016.05.227.

[12] BRASIL. Ministério da Saúde. Sistemas de Informaçóes de Mortalidade - DATASUS. Mortes por causas externas no período 2000-2015. Disponível em: <http://www2.datasus.gov.br/DATASUS/index.php?area=02>. Acesso em: 10 ago. 2017.

[13] BRASIL. Ministério das Cidades. Departamento Nacional de Trânsito - DENATRAN. Frota de veículos no período 2000-2015. Disponível em: <http:/www.denatran.gov.br/frota.htm>. Acesso em: 10 ago. 2017.

[14] BRASIL. Ministério do Planejamento Orçamento e Gestão. Instituto Brasileiro de Geografia e Estatística IBGE. População no Brasil de 2000-2015. Disponível em: <https:/ww2.ibge.gov.br/home/estatistica/populacao/ projecao_da_populacao/2013/default_tab.shtm>. Acesso em: 10 ago. 2017.

[15] COMISSÃO EUROPEIA (Org.). Road Deaths per million Inhabitants 2015: Pedestrians. Bruxelas: Comissão Europeia, 2017. 